streptococcic polyvalent serum may help; it will certainly do no harm. Stock vaccines are dangerous, and are not held to be sound practice. If an autogenous vaccine can be prepared in very small initial doses, good results may occasionally be got, but it should be carefully used.

(c) In infective subacute endocarditis. In addition to hygiene, nourishment and stimulants, the only treatment with any chance of success seems to be a vaccine (autogenous) or horse serum; antistreptococcic and similar vaccines are useless. Even vaccines show no record of value. Horder and Libman's suggestion to adopt preventive measures in all cases of cardiac lesions of inefficiency by immunizing patients with vaccines of Streptococcus anhaemolyticus (or viridans) is sound, and the ouly hope so far.

(d) In rheumatoid aithritis. Much can be done by steady perseverance in raising the general health by diet, clothing, exercise, and climate. Guaiacol carbonate, salol, and quinine salicylate help to eliminate the rheumatoid poison. The urine odour is some guide to this elimination. Iron as iodide with malt and arsenic is useful in improving tissue tone. Radium, in waters, prom:ses good results. Electric and thermal treatments liave their partial successes, but vaccines are giving more hopeful results on autogenous lines, being. prepared from cultures from the teeth, throat, faeces, or urino. Phylacogens prepared from rheumatic streptococci, etc., I have had experience of, but cannot speal of any success. The disease may be due to several infections; if you can find the definite organism, or organisms, autogenous vaccines would possibly do well.

In conclusion, it is evident that we know very little as to the incidence, varying virulence, and selective distribution of pathogenic and pyogenic bacteria. There is a great field of research open to the collaboration of anatomist, bacteriologist, pathologist and dental surgeon. We in this Border Counties area miss much of the clinical picture in difficult and obscure cases through want of a local pathological department. . As to treatment, we must have contidence in future research, so that our treatment may become less empirical and general, and more scientific and accurate.

\section{THE END-RESULTS OF SANATORIUM TREATMENT} OF TUBERCULOSIS :

\section{A Record of Seventeen Years' Sanatorium Work.} BY

F. W. BURTON-FANNING, M.D.CAMB., F.R.C.P.; HONORARY PHYSTCIAN TO THE NORFOLK AND NORWICH HOSPITAL, KELLING BANATORIOM, AND STANNINGHAIL TUBERCULOSIS COLONY; AND

W. J. FANNING, B.A.Oxon., M.R.C.S., L.R.C.P., LATE RESIDENT MEDIGAL OFFICER, KELLING SANATORIOM.

Tue results of sanatorium treatment of patients from the industrial classes have recently been the subject of a good deal of criticism. We propose to publish figures setting forth up to date what has happened to patients admitted to Kelling Sanatorium between 1903 and 1919 , and to let these figures speak for themselves. One of us (W. J. F.) has devoted a great deal of time to keeping in touch by continual visits and letters. with all our old patients. The only claim we make for this publication is that our patients have perhaps been followed up more closely than is practicable in larger cities, or with more shifting rural populations.

Between 1903 and 1919 sanatorium treatment was given to 3,220 patients. : Of this number 460 lave been lost sight of, so there remain for consideration 2,760 patients, whose fate at the end of 1921 is here given:

Treated at sauatorium from 1903 to 1919 ... 2760

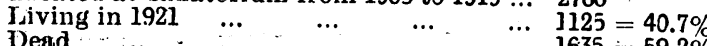

$$
\begin{aligned}
& \text {... } 1635=59.2 \%
\end{aligned}
$$

Our paticnts on admission were classed as follows:

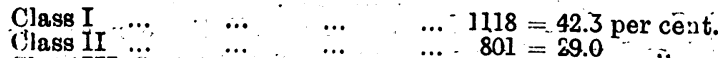

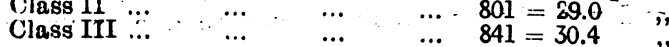

Before comparing these figures with those published by $\mathrm{Dr}$ Noel Bardswell in the November issue of Tubercle, and in his memorandum to the London Insurance Committee, we must explain that we have been obliged to adhere to our original classification.
Dr. Bardswell's * Class I inoluded only 25 per cent. or less of the total number of applicants; but his definition of this group is limitation of physical signs to the apex of one or both lungs, and the apex is considered as that part accessible to examination in the supraclavicular and supraspinous fossae. We quite agree with this restriction for Class I cases, but in the present communication that class includes cases whose physical signs denoted the involvement of an area of lung not exceeding that of one lobe, provided that severe constitutional symptoms and complications were absent.

In regard to ultimate results according to classification on admission to the sanatorium, Dr. Bardswell a!so emphasizes the great importance of the presence or absence of tubercle bacilli in the sputum. We are unable to make this distinction with our cases. In an immense majority the tubercle bacillus was demonstrated in the sputum; in the remainder we only concerned ourselves to obtain other unequivocal evidence that the patient was affected with tuberculosis of the lung.

The next table shows the different results according to the patient's classification on admission:

$$
\begin{array}{llrllll} 
& & & \multicolumn{2}{c}{\text { Living. }} & & \text { Dead. } \\
\text { Class I } & \ldots & 1118 & \ldots . . & 724=64.7 \% & \ldots . . & 394=35.2 \% \\
\text { Class II } & \ldots & 801 & \ldots \ldots . & 274=34.2 \% & \ldots \ldots . & 527=65.7 \% \\
\text { Class III } & \ldots & 841 & \ldots \ldots . & 127=15.0 \% & \ldots \ldots . & 714=84.8 \%
\end{array}
$$

If, therefore, we confine ourselves to the consideration of the more favourable class of applicants for treatment, instead of a mortality of 59.2 per. cent. we get a mortality of 352 per cent. for the nineteen years. It is interesting to contrast these figures with those of Dr. Bardswell. His first class were, as we have scen, more strictly selected and their mortality was about 30 per cent., but his period embraced only four years. The excessive mortality which occurs during the first few years after discharge from the sanatorium is a point to which we shall refer shortly. The real crux of the matter, however, is the durability of the restorations of health obtained by sanatorium treatment. The next table gives the percentage of our patients now known to be living and to have died, arranged in their classes and according to

\begin{tabular}{|c|c|c|c|c|c|c|c|}
\hline \multirow{2}{*}{\multicolumn{2}{|c|}{ Years. }} & \multicolumn{2}{|c|}{ Class I. } & \multicolumn{2}{|c|}{ Class II. } & \multicolumn{2}{|c|}{ Class III. } \\
\hline & & Living. & Dead. & Living. & Dead. & Living. & Dead. \\
\hline $190 z-1905$ & $\cdots$ & 44.0 & 56.0 & 24.0 & 86.0 & 4.3 & §5.7 \\
\hline $1905-1508$ & $\cdots$ & 54.5 & 45.5 & 202 & 73.8 & 8.8 & 912 : \\
\hline $1903-1911$ & $\ldots$ & $56: 8$ & $-43: 2$ & $18.5^{-}$ & $81.5^{\circ}$ & 8.4 & 916 \\
\hline $1912-1914^{-}$ & $\ldots$ & 58.0 & 42.0 & 365 & 63.5 & 14.4 & 85.6 \\
\hline $1315-1917$ & $\ldots$ & 617 & 38.3 & 43.9 & 56.1 & 21.3 & 78.7 \\
\hline
\end{tabular}
the year of their discharge from sanatorium. We would repeat that our Class I was too broad and included a number of cases that we would now place in Class II.

Percentage Discharged.

Of our Class I patients who left the sanatorium between 1903 and 1908; so long aco as thirteen to nineteen years about one-half are, therefore, still alive. The crucial period is the first four or five years after treatment, and of those who survive this time a large proportion maintain their ascendancy over the malady for an indefinite number of years. This point is forcibly brought out by tlie next table, which gives the percentages of deaths occurring in tive-year periods subseguent to discharge from the sanatorium

Of those that died, death occurred as follows:

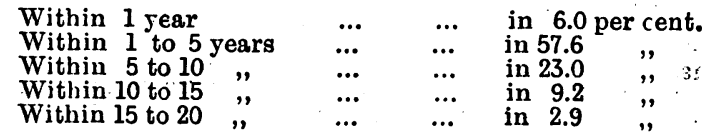

Of all the patients who died after receiving sanatorium treatment, the average length of time between the appearance of the first definite symptom and death was just over five years. Publications which dwell on the number of deaths which occur within a few years of leaving the sanatotium give, in our opinion, an unnecessarily gloomy aspect of the story.

* This classification is that adopted by the London County Council Public Health Department after consultation with the Tuberculosis Department of the Ministry of Health. 
The immediate general improvement and the definite control of important symptoms brought about by sanatorium treatment are not called in question. We are concerned, however, about the proportion of patients who relapse soon after resuming their ordinary modes of life. In our conflict with consumption the part played by the sanatorium must, in our existing state of knowledge, be considered satis. factory, but the treatment needs to be commenced earlier and finished differently. The two directions in which reforms must be made for the purpose of securing more lasting recoveries are those of earlier diagnosis and better organized after-care. The advantage of placing the patient under treatment at an early stage of the malady is testified to by the records of all sanatoriums. Our first class embraced numbers of patients whose signs were reproachfully obvious and extensive, and yet about half of them have lived for fifteen years or more, mostly able to do some kind of work.

When we appreciate the supreme importance of early diagnosis the classification of cases of pulmonary tuberculosis deserves much consideration. We welcome Dr. Bardswell's proposal as marking a distinct advance in what we should aim at, for classification is used not only to provide conrenient headings for the grouping of cases. His Class I, as defined above, represents a stage of the disease beyond which it should be our aim to let no patient go before he is caught and sent to a sanatorium. Dr. Bardswell's wide experience in connexion with the London Insurance Committee is that only 25 per cent. of applicants for treatment are Class I cases. In a communication we made to the British Medical Journal (August 24th, 1912, p. 409) concerning over 1,000 patients, we stated that eighteen months was the average time allowed to elapse between the first obvious manifestation of the malady and the application for sanatorium treatment.

There has certainly been improvement in this all-important direction of earlier diagnosis and treatment. The increasing numbers of expert tuberculosis officers who are at the service of the practitioner in the search for eurly cases must bear fruit. It was a great move when facilities were made for getting the sputum of any person examined, and as more and more advantage is taken of the public laboratory the practitioner will detect a larger proportion of his consumptive patients in their early stages. Pulmonary tuberculosis should be thought of whenever a cough cannot be otherwise satis. factorily accounted for. We are sure that a number of febrile illnesses of obscure nature owe their origin to tuberculosis. The systematic observation of the temperature in the latter part of the day is now made easier, thanks to the larger number of visiting nurses. A slight degree of fever in the afternoon for day after day, with no symptom perhaps beyond a little tiredness or loss of weight, is very suggestive of tuberculosis. Supposing there is no sputum and the diagnosis cannot be clenched by an examination of that for the bacillus, there is now radiology to be appealed to. In the hands of an expert the evidence of an $x$-ray examination of the chest may in a large proportion of cases be accepted as proving or disproving tuberculosis. We are certain from our experience that in every centre $x$-ray examination should be available for the diagnosis of doubtful cases.

A history of certain previous illnesses may arouse the suspicion of existing pulmonary tuberculosis. It is increasingly realized that pleurisy in the absence of pueumonia, rheumatism, septicaemia, or nephritis, must be regarded as tuberculous. Every patient who has liad tuberculous pleurisy should be given a course of sanatorium treatment with a view to preventing the subsequent possible involvement of thie lungs. In our cases of pulmonary tuberculosis there was a definite history of antecedent pleurisy, which had been apparently recovered from, in no fewer than 22.4 per cent. Undoubtedly to this number might be added others who had suffered from unrecognized or forgotten pleurisy. According to some observers, 40 per cent. of patients who have had primary pleurisy eventually develop pulmonary taberculosis. There are good grounds, therefore, for giving all these patients the advantage of a precautionary course of sana. torium treatment.

It is contended by some writers nowadays that certain tuberculous manifestations have the effect of rendering the individual immune to pulmonary tuberculosis. Glandular affection, for instance, is stated by some to be always of bovine type, and to protect from lung disease. But of our patients with pulmonary tuberculosis 4 per cent. had previously suffered from glandular abscesses, and our strong impression is that this understates the frequency of the association. In hospital and in private practice one of us (F.W. B.-F.) has seen too many cases of pulmonary disease supervening on tuberculosis of glands to be ascribed to coincidenco. In some of these the pulmonary tuberculosis lias been of acute type, and it has been difficult to resist the suggestion that surgical interference with the glands or their treatment by tuberculin had stirred up the trouble.

Just under 3 per cent. of our sanatorium patients had previously suffered from tuberculous disease of bones or joints. We think that this by no means represents the actual frequency of tuberculosis of lungs and of bones in the same patient. Surgical tuberculosis is excluded from the sana. torium, but amongst hospital patients it.is not uncommon to find combined disease of lunge, bones, joints, and other parts. There is a well recognized form of tuberculosis in which one or both pleurae are apt to be affected with the peritoneum, and at the present time there is a patient in the Norwich Hospital suffering from tuberculous peritonitis and double tuberculous pleurisy from whom tuberculous glands had been recently removed.

Fistula in ano had occurred in only 0.5 per cont. of our sanatorium patients previous to their lung trouble, but it is, of course, more common as a subsequent event. Tuberculous disease of the eye, of the epididymis, and of the Fallopian tube were mentioned in the past histories of a still smaller proportion of our patients. It should be unnecessary nowadays to insist that haemoptysis of any amount ap. proaching a teaspoonful, and without other obvious explauation, is to be taken as evidence of pulmonary tuberculosis, but fatal mistakes are still made about this. In a number of cases pulmonary tuberculosis is said to have followed some other malady. Influenza is given as a particularly frequent precursor, but proof of the exact nature of the illuess is difficult to obtain. We would lay more stress on the point that in the light of after events tuberculosis is the possible explanation of many attacks of ferer which at the time cannot be diagnosed withont the assistance of the specialist in $x$ rays or in bacteriology, and perhaps even their evidence may be inconclusive.

A most fruitful field for the activity of the tuberculosis officer lies in his detection of the earliest-cases by the fnspec. tion of so-called "contacts." 'To digress, we think that the use of this word is the begging of an important question. W.e are not convinced that the main cause of tuberculosis is the infection of the infant or child with the tubercle bacillus from a patient. Without attempting to present the arguments on this point, we would only say that from an unbiassed inquiry into the histories of our patients, we thought there was evidence of case-to-case infection of an adult in a very ferv instances only. In at least 50 per cent. of our cases there was a history of tuberculosis in a parent or brotlier or sister. According to some writers, these were instances not of heredity, but of infection. How do we explain on this theory the commonly observed fast that one brotler or sister after another in a family develops tuberculosis, though neither parent has ever shown any symptom of the disease and though the children for many years had occupied.different homes. Again, it is not exceedingly rare to trace the supposed hereditary susceptibility to a parent whose tuberculosis declared itself in disease of bone, joint, or abdomen, where no obvious diffusion of the bacillus took place. Whichever doctrine we adopt we sluall agree that the existence of tuberculosis in a relation or the history of certain previous illnesses in the individual would be grounds for looking at him with increased suspicion.

The second direction in which we must aim at improvement is the after-care of our patients. In regard to this the one essential point, according to our experience, is securing for all ex-sanatorium patients continuous supervision by an expert. However thoronghly the patient has been instructed in after-care at the sanatorium, a small proportion only show themselves able to follow the precepts. So manifest an in. dication of trouble as persistent rise in temperature the patient may have noted but may elect to disregard, or more probably the ex-patient has broken the thermometer, or anyhow has rot kept the enjoined wateli on his temperature. There are numberless other points which indicate whether or not the consumptive is holding his ground, but the trained eye is needed to appreciate tirem.

It is only at a sanatorium that the real importance of attention to minutiae is grasped, and the advantage of having ex-sanatorium patients under the continued observation of a nurse or doctor who has had this training is obvious. The generally accepted rules of sanatorium treatment have been strictly followed by us, and continued experience has led 
to little modification. From the first the patient's exercise took the form of useful work. For more than a year tuberculin was given systematically to a certain group of the patients, but we were not favourably impressed by it.

There has been a farm colony on a small scale in Norfolk for the last eighteen months, and the experience gained there has been most instructive. Generally speaking, the way in which the men's healths have been maintained, or more commonly improved, while they followed some useful occupation, has been highly encouraging. Some of the colonists came to us with the sputum already free from tubercle bacilli, and with signs of only past mischief. With only one or two exceptions these men have gone steadily forwards, and under the conditions of healthy housing, of good feeding, and of regulated work have required little attention. But the men with bacilli still present, and with physical signs placing them perhaps in Class II, have had to be watched more carefully. Even of them the majority have done surprisingly well. At the same time a week seldom passes without one of the colonists being pulled up with the threat of a smaller or greater set-back. Apart from elevation of temperature from increased frequency of pulse or from loss of weight, the jealous eye of the nurse notices loss of appetite or some other indication of lowered health. When this man is examined it may often be found that, sure enough, an extension of his disease has occurred.

Tuberculosis in all its phases is characterized by a broken course with ups and downs, and success in its management depends on any tendency to relapse being immediately detected and properly dealt with. This essential require. ment in the after.care of the ex-sanatorium patient seems to us to be best met by the colony scheme. For the man whose tuberculosis has become arrested it is not of supreme importance whether his employment be out of doors or indoors. Of course it is an advantage if he can spend twenty-four hours each day in the fresh air, but it is of more importance to provide that the number of hours and the arduousness of the work be strictly regulated according to the man's ascertained capability.

Some years ago we got out figures for the purpose of comparing the after-results in our ex-sanatorium patients, according to their resumption of an indoor occupation, to their resumption of an outdoor occupation, or to their changing from indoor to outdoor work. Our statistics showed, however, no striking differences among the three groups. We know that there are many factors to be taken into consideration, such as the healthiness or the reverse of the workroom, the home conditions, the amount of the earnings, and the consequent sufficiency or scarcity of good food, and chiefly whether or not the individuals are worked beyond their strength. Our agricultural labourers, for instance, have not yielded good after-results. Their working hour's are spent in the open air, but we know that their toil is arduous, that they are often badly housed, and have been badly fed. On the other hand, the few master farmers who have passed through the sanatorium have mostly continued to do well. Presumably they were able to choose their kind and amount of work, and, of course, they were able to live well.

While indoor work as such is not necessarily harmful, so long as it is not too strenuous, there is information in regard to certain industries which marks them as unfavourable for the ex-sanatorium patient. In Norwich, for example, the clerk of the City Insurance Committee finds that, of 439 men applying for sanatorium benefit, 33.5 per cent. were working. in boot factories, and that of 297 women 20.2 per cent. were thus employed. Our sanatorium patients who were forced by circumstances to return to the boot factories have done no better than we should have expected. They are unfitted to take their places beside able-bodied men and to work full time at top speed and perhaps under unhealthy conditions. The experience at Papworth and elsewhere shows, however that the consumptive man can do remunerative work in the model factory, so long as his exertions are adjusted to his physical powers.

Dr. F. Stanley Tinker suggests the institution of municipal workshops, the men going backwards and forwards from their homes, and working under medical supervision. There may be other solutions of the problem, but we are convinced that for the first five years at least the patient with pulmonary tuberculosis should be kept under close and expert super vision. Such work should be allowed as is found to be compatible with the retention of his ascendancy over the disease. He must be relieved of anxiety about the maintenance of himself and his dependants, his housing must be seen to, and there must be no difficulty in securing for him return to the sanatorium from time to time if his malady reasserts itself. The difficulty of such provision is, of course, the financial one, but unless this difficulty is overcome part of the expenditure on sanatoriums is thrown away. We know that it is possible not only to prolong the lives of these men, but to make them useful members of the community.

\section{HAEMORRHAGIC COLITIS.}

BY

J. IV. GEARY GRANT, F.R.C.S.ENG.,

SENIOR ASBISTANT SURGFON, RING RDWARD VII HOSPITAL, AND CHIEP ASSISTANT IN THE BORGICAL UNIT, WELSH NATIONAL

The following two cases, which, in view of the fact that haemorrhage and the resulting severe anaemia were the leading symptoms, I have ventured to term "haemorrhagic colitis," were in the King Edward VII Hospital about the same time under the care of Dr. Mitchell Stevens, to whose courtesy and to that of Mr. Cornelius Griffiths, who operated on the first case, I am indebted for permission to give this account.

\section{Case r.}

The patient, a housemaid aged 37, stated that for fourteen days she had passed a quantity of blood and mucus in the motions, which averaged five a day. She had had an attack of "dysentery", at Regina, Canada, in 1917, and two similar attacks subsequently. When examined on October 26th, 1920, the temperature was normal. The faeces contained blood, mucus, and pus cells, and $B$. coli. An autogenous vaccine was prepared and administered At Dr. Mitchell Stevens's request I examined her with the sigmoidoscope, but was unable to get the instrument past the pelvic brim. This was largely oring to the continual flow of blood which obscured the view. The pelvic colon had a granular appearance, and in the upper part there were numerous papillary elevations, the mucous membrane bleeding at the slightest touch. No definite ulcers were seen, but the appearance at the upper part of the pelvic colon suggested carcinoma to me

On November 28th, 1920, Mr. Cornelius Griffiths opened the abdomen by a median subumbilical incision and drew out the iliac colon which was found to be thickened. A portion of the wall was removed for examination and reported to be haemangiomatous. There was not, however, any localized growth but a diffuse thickening of the mucous membrane. A faecal fistula was established. For a month the temperature was irregular, averaging $100^{\circ}$ to $101^{\circ}$. Blood and pus passed from the colostomy opening and from the anus, and staphylococci were found in the urine. The Wassermann reaction was negative.

On January 14th, 1921, Mr. Griffiths closed the fistula, and in May she was discharged to a convalescent home, all symptoms having cleared up.

CAse II.

This patient, a clerk aged 21, was admitted under the care of Dr. Mitchell Stevens on January 17th, 1921 . He stated that for month before admission he had passed large quantities of blood from the anus, and that he had passed blood also in small quantities for eighteen months previously; he suffered no pain. He had had no previous illnesses, lived in a mining district, and had not been abroad. The rectum was washed out, and the returned fluid contained blood, pus and. mucus. On January 20th, at Dr. Mitchell Stevens's request, I passed a sigmoidoscope, but I could not get it past the angulation at the pelvic brim. "The appearance was almost exactly the same as in the previous case. There was a continual flow of blood from the granular and friable mucous continual flow of blood from the granular and friable mucous
membrane of the pelvic colon. He was extremely anaemic and membrane of the pelvic colon. He was extremely. anaemic and
emaciated, and Dr. Mitchell Stevens felt that immediate surgical intervention was needed; the opinion we formed was that he probably had a polypus or imultiple adenomata in the colon.

On January 26 th, 1921, I opened the abdomen by a median subumbilical incision and drew out the iliac colon. Its wall was thickened and firm; the para-colic lymph glands were enlarged and two were removed for examination. A portion of the wall of the colon was also removed, and the report on this was wat it showed a haemangiomatous condition of the mucous membrane, showed a haemangiomatous condition of the mucous membrane, a. sigmoidoscope as far as the splenic flexure. The mucous mem brane simply presented a granular appearance and intense engorge ment and bled at a touch. There was no ulceration. As his condition was very bad, I fixed the loop of iliac colon in the wound and established a colostomy with a good spur. He was very collapsed after the operation, but with rectal saline and glucose he came round, but for two days vomited a good deal. The he came round, but for two days vomited a good deal. The
colostomy discharged pus and mucus freely, with small amounts colostomy discharged pus and mucus freely, with small amounts
of blood. It was washed out with saline and with collargol, and horse serum and calcium lactáte were administeréd.

A blood examination on February 2nd showed haemoglobin 65 per cent.; red blood cells, $3,640,000$; white cells, 16,000 ; the differential count gave polymorphs 76 per cent. small lymphocytes 10 per cent., large lymphocy tes 6 per cent., eosinophils 3 per cent., myelocytes 5 per cent. 